Accepted refereed manuscript of: Zietsch BP, Sidari MJ, Murphy SC, Sherlock JM \& Lee AJ (2021) For the good of evolutionary psychology, let's reunite proximate and ultimate explanations. Commentary on: A.J. Lee, M.J. Sidari, S.C. Murphy, J.M. Sherlock, B.P. Zietsch Sex differences in misperceptions of sexual interest can be explained by sociosexual orientation and men projecting their own interest onto women $P$ sychological Science, 31 (2020), pp. 184-192. Evolution and Human Behavior, 42 (1), pp. 76-78. https://doi.org/10.1016/j.evolhumbehav.2020.06.009 (c) 2020, Elsevier. Licensed under the Creative Commons Attribution-NonCommercial-NoDerivatives 4.0 International http:// creativecommons.org/licenses/by-nc-nd/4.0/

\title{
For the good of evolutionary psychology, let's reunite proximate and ultimate
}

\section{explanations}

In Lee et al. (2020), we showed using a large speed dating study that sex differences in misperceptions of sexual interest can be explained by sociosexual orientation and, primarily, the tendency to project one's own interest onto others. We suggested that our results called into question the influential theory that the sex difference in misperception of sexual interest evolved via sex-specific specialized adaptations because it is advantageous for men, relative to women, to overperceive sexual interest (error management theory; EMT). Roth, Samara, and Kret (2020) criticise our interpretation, claiming that 1) our analyses are confounded and 2) we have confused proximate and ultimate levels of explanation. We reject both claims, but the second is an interesting and important issue that has arisen repeatedly in discussions of our paper, as well as in other contexts in the broader literature on evolution and human behaviour. We spend some time discussing why proximate explanations are crucial to a healthy evolutionary psychology, and why we believe evolutionary psychologists should pay more attention to them.

First, though, we address Roth et al.'s claim that “It is not surprising that sex differences in the overperception bias disappeared when adding these mediating variables, as the sex differences in the mediators are confounding their main analysis." Roth et al. marshal evidence, both from the literature and their analysis of our own data, that our mediators

(sociosexuality and own sexual interest) differ by sex, as if this is new information devastating to our argument. But the entire rationale of our study relies on these wellestablished sex differences, which we explained at length in the Introduction of Lee et al. (2020; p 185). For mediation to exist, the mediator must be associated with both the independent variable (sex) and the dependent variable (misperception of sexual interest) 
(Baron and Kenny 1986). In other words, for mediation to exist, the mediator variables must differ by sex. It therefore does not make sense to claim, as Roth et al. do, that sex differences in the mediators confounded our analyses.

We also note that we did not "cast doubt on the validity of previously described sex differences in sexual overperception bias", as Roth et al. claim. Indeed, we showed the same overperception bias in our own data (see Base Model effect for Sex, Figure 1). Roth et al. also call our conclusion that the sex difference in misperception of sexual interest disappears when the mediators are controlled for "unwarranted" and "not justified". This effect is simply an empirical observation, not our conclusion.

The proximate-ultimate distinction should not be used to shield ultimate explanations from scrutiny

With regard to the proximate-ultimate distinction (Tinbergen 1963), there are two common kinds of erroneous thinking in the evolutionary social sciences. One kind is well recognised: the mistake of conflating proximate and ultimate levels of explanation (see ScottPhillips et al. 2011for discussion and examples). This is the mistake Roth et al. suggest we made in Lee et al. (2020), even though we discussed this very issue (p. 190). The second kind is perhaps more pernicious because it is not well recognised: the mistaken belief that ultimate explanations have nothing to say about proximate mechanisms, and vice versa. This is the error that Roth et al. make. They say: "EMT is primarily concerned with the ultimate causes of behavior, and remains 'virtually silent' about the proximate causes (Haselton \& Galperin, 2013, p. 249)”. But just because researchers proposing an ultimate explanation do not specify a proximate explanation, it does not follow that the nature of the proximate explanation has no implications for the ultimate explanation. On the contrary, the proximate explanation can represent strong (or weak) evidence for or against a given ultimate explanation. 
The illustrative example Roth et al. use of a proximate explanation (testosterone correlating with singing in birds) happens to be perfectly consistent with the ultimate explanation (birds sing to attract mates). This is because 1) there tends to be more competition for mates among males, 2) males tend to sing more than females, and 3) making a trait dependent on sex hormone levels is the primary way evolution creates adaptive sexual dimorphism. But the fact that this particular proximate explanation is consistent with this particular ultimate explanation does not mean that any proximate explanation is consistent with any ultimate explanation.

Imagine, for example, that Researcher A hypothesises that humans should tend to be scared of snakes because of an evolutionary history in which snakes often killed people, meaning fear of snakes provided a fitness advantage. She performs a study showing that people do indeed tend to fear snakes. Researcher A concludes that her research supports the ultimate explanation on which the hypothesis was based. Researcher B challenges this conclusion by raising the possible proximate explanation that people learn to fear snakes in the course of their lives. Researcher A replies that B has made a classic proximate-ultimate confusion: associative learning is the proximate explanation, which says nothing about the ultimate explanation (an evolutionary history in which snakes often killed people).

We hope the problems with Researcher A's claims are obvious in this example. Learning is a general process not specific to snakes. Therefore, if learning is required to fear snakes, there need not be any special ultimate explanation required for fear of snakes. On the other hand, if fear of snakes emerges in a manner beyond what can be explained by general learning principles, such as it being present from birth or being more easily learned than fear of other animals or objects, then we might invoke an ultimate explanation. In reality, the question of whether an ultimate explanation for fear of snakes is necessary is still being debated a half-century after the hypothesis was proposed (Seligman 1971), and the grist of 
the debate includes, to a large degree, the details of the proximate mechanisms of fear of snakes (Coelho et al. 2019).

As well as providing a useful illustration of why proximate explanations matter for ultimate explanations, the above example also provides a loose analogy to the findings of Lee et al. (2020). We found that projection - an individuals' tendency to project their own sexual interest onto their speed-date partners - almost fully (98\%) mediated the sex difference in over-perception of sexual interest. Does projection make sense as a proximate mechanism for the ultimate explanation provided by error management theory (that sex differences in overperceptions of sexual interest have evolved as a specialized adaptation to sex-specific selection pressures)? Inconsistent with that possibility is the fact that the tendency to believe others feel similarly to oneself is a general phenomenon not specific to sexual attraction (Marks and Miller 1987; as we note in Lee et al. 2020), just as learning is a general process not specific to snakes. Because men tend to have greater sexual interest in opposite-sex strangers than do women (a sex difference that has its own distinct ultimate explanation, just as learning has its own ultimate explanation), and because people tend to believe others feel similarly to themselves (a general phenomenon for which the ultimate explanation is unclear), sex differences can be predicted to emerge in the over-perception of sexual interest without the need for a specific ultimate explanation.

Even if projection were not a general phenomenon and were instead limited to sexual interest, would it make sense as a proximate mechanism for error management theory? This depends on the specification of the theory. As it was formulated with regard to misperception of sexual interest (Haselton and Buss 2000), error management theory identifies the ultimate source of sexual misperception as the difference between male and female costs and benefits of over- and under-perception (the evolutionary logic of these male-female differences is based on parental investment theory, which ultimately derives from the different cost of male 
and female gametes (Trivers 1972; Haselton 2003)). Haselton and Buss's formulation does not invoke a role for one's own sexual interest, so it provides no reason to predict evolution would have created a sex difference in sexual misperception via the needlessly complex route of evolving a psychological mechanism that links bias towards sexual overperception with individuals' own sexual interest. In fact, Haselton and Buss (2000) explicitly contrast error management theory with "the default-model hypothesis, which is closely related to the false consensus model in social-cognitive research (see Marks \& Miller, 1987, for a review). This hypothesis suggests that men exceed women in sexual desire and use their own desires as an erroneous gauge of women's desires (Shotland and Craig 1988)” (p. 82). That is, Haselton and Buss regarded projection as an alternative to error management theory, not as its potential mechanism.

To be properly falsifiable and therefore useful, ultimate explanations must meaningfully connect with data - not only endpoint observations like men overperceiving sexual interest or people fearing snakes, but the proximate mechanisms by which such effects arise. But there seems to be a belief common among evolutionary psychologists that our domain of interest is ultimate explanations and that proximate explanations are the concern of others. This belief does our ultimate explanations a huge disservice. Not only does it mean that we often dismiss information that points to a disconnect between theory and data (as Roth et al. do), which stymies the correction and refinement of ultimate explanations - worse, the belief tends to prevent us from looking for this information in the first place. Disinterest in proximate explanations may partly explain why genetics, the quintessential proximate explanation, has played so limited a role in evolutionary psychology despite underlying to varying extents all the behaviours we are interested in. Behavioural genetics findings can create considerable problems for existing ultimate explanations (e.g. Zietsch and Santtila 2011; Lee et al. 2014; Zietsch 2016; Sherlock and Zietsch 2017; Zietsch and Sidari 2019). 
Ignoring these findings does not protect ultimate explanations, it only shields them from scrutiny - and it closes off opportunities for strengthening the explanations and developing new ones (see Zietsch et al. 2015 for a review). The same applies to non-genetic study of other proximate explanations.

To conclude, we argue that Roth et al.'s commentary reflects a costly tendency among evolutionary psychologists to ignore or dismiss proximate explanations as irrelevant to the ultimate explanations of real interest. We call on evolutionary psychologists to devote more attention and study to proximate explanations of behaviour, and to look for evidence relating to proximate mechanisms that might support or disconfirm ultimate explanations. Although there will rarely be a one-to-one link across these levels of understanding, uniting proximate and ultimate explanations will only strengthen the field.

\section{References}

Baron, R. M., and D. A. Kenny. 1986. The moderator-mediator variable distinction in social psychological research: Conceptual, strategic, and statistical considerations. Journal of Personality and Social Psychology 51:1173-1182.

Coelho, C. M., P. Suttiwan, A. M. Faiz, F. Ferreira-Santos, and A. N. Zsido. 2019. Are humans prepared to detect, fear, and avoid snakes? The mismatch between laboratory and ecological evidence. Frontiers in Psychology 10.

Haselton, M. G. 2003. The sexual overperception bias: Evidence of a systematic bias in men from a survey of naturally occurring events. Journal of Research in Personality $37: 34-47$.

Haselton, M. G., and D. M. Buss. 2000. Error management theory: A new perspective on biases in cross-sex mind reading. Journal of personality and social psychology 78:81. 
Lee, A. J., D. G. Mitchem, M. J. Wright, N. G. Martin, M. C. Keller, and B. P. Zietsch. 2014. Genetic factors that increase male facial masculinity decrease facial attractiveness of female relatives. Psychological Science 25:476-484.

Lee, A. J., M. J. Sidari, S. C. Murphy, J. M. Sherlock, and B. P. Zietsch. 2020. Sex differences in misperceptions of sexual interest can be explained by sociosexual orientation and men projecting their own interest onto women. Psychological Science 31:184-192.

Marks, G., and N. Miller. 1987. Ten years of research on the false-consensus effect: An empirical and theoretical review. Psychological Bulletin 102:72-90.

Scott-Phillips, T. C., T. E. Dickins, and S. A. West. 2011. Evolutionary Theory and the Ultimate-Proximate Distinction in the Human Behavioral Sciences. Perspect. Psychol. Sci. 6:38-47.

Seligman, M. E. P. 1971. Phobias and preparedness. Behavior Therapy 2:307-320.

Sherlock, J. M., and B. P. Zietsch. 2017. The link between deprivation and its behavioural constellation is confounded by genetic factors. Behavioral and Brain Sciences 40:e343.

Shotland, R. L., and J. M. Craig. 1988. Can men and women differentiate between friendly and sexually interested behavior? Social Psychology Quarterly 51:66-73.

Tinbergen, N. 1963. On aims and methods of ethology. Zeitschrift für tierpsychologie $20: 410-433$

Trivers, R. L. 1972. Parental investment and sexual selection. Pp. 1871-1971 in B. Campbell, ed. Sexual selection and the descent of man. Aldine, Chicago, IL.

Zietsch, B. P. 2016. Individual differences as the output of evolved calibration mechanisms: does the theory make sense in view of empirical observations? Current Opinion in Psychology 7:71-75. 
Zietsch, B. P., T. R. de Candia, and M. C. Keller. 2015. Evolutionary behavioral genetics. Current Opinion in Behavioral Sciences 2:73-80.

Zietsch, B. P., and P. Santtila. 2011. Genetic analysis of orgasmic function in twins and siblings does not support the by-product theory of female orgasm. Anim. Behav. 82:1097-1101.

Zietsch, B. P., and M. J. Sidari. 2019. A critique of life history approaches to human trait covariation. Evolution and Human Behavior. 